\title{
BMJ Open Recognition of, and attitudes towards, people with depression and psychosis with/without alcohol and other drug problems: results from a national survey of Australian paramedics
}

\author{
Terence V McCann, ${ }^{1}$ Michael Savic, ${ }^{2,3}$ Nyssa Ferguson, ${ }^{2}$ Alison Cheetham, ${ }^{2,3}$ \\ Katrina Witt, ${ }^{2,3}$ Kate Emond, ${ }^{4}$ Emma Bosley, ${ }^{5}$ Karen Smith, ${ }^{6}$ Louise Roberts, ${ }^{7}$ \\ Dan I Lubman ${ }^{2,3}$
}

To cite: McCann TV, Savic M, Ferguson $\mathrm{N}$, et al. Recognition of, and attitudes towards, people with depression and psychosis with/without alcohol and other drug problems: results from a national survey of Australian paramedics. BMJ Open 2018;8:e023860. doi:10.1136/ bmjopen-2018-023860

- Prepublication history for this paper is available online. To view these files, please visit the journal online (http://dx.doi. org/10.1136/bmjopen-2018023860).

Received 30 April 2018

Revised 23 July 2018

Accepted 11 October 2018
Check for updates

(C) Author(s) (or their employer(s)) 2018. Re-use permitted under CC BY-NC. No commercial re-use. See rights and permissions. Published by BMJ.

For numbered affiliations see end of article.

Correspondence to Dr Terence V McCann; terence.mccann@vu.edu.au

\section{ABSTRACT}

Objective Continuing stigma towards mental health problems means that many individuals-especially menwill first present in crisis, with emergency services often the first point of call. Given this situation, the aims of this paper were to assess paramedics' ability to recognise, and their attitudes towards, males with clinically defined depression and psychosis with and without comorbid alcohol and other drug (AOD) problems.

Methods A cross-sectional national online survey of 1230 paramedics throughout Australia. The survey was based on four vignettes: depression with suicidal thoughts, depression with suicidal thoughts and comorbid alcohol problems, and psychosis with and without comorbid AOD problems.

Results Just under half of respondents recognised depression, but this decreased markedly to one-fifth when comorbid AOD problems were added to the vignette. In contrast, almost $90 \%$ recognised psychosis, but this decreased to just under $60 \%$ when comorbid AOD problems were added. Respondents were more likely to hold stigmatising attitudes towards people in the vignettes with depression and psychosis when comorbid AOD problems were present. Respondents endorsed questionnaire items assessing perceived social stigma more strongly than personal stigma. Desire for social distance was greater in vignettes focusing on psychosis with and without comorbid AOD problems than depression with and without comorbid AOD problems.

Conclusions Paramedics need a well-crafted multicomponent response which involves cultural change within their organisations and more education to improve their recognition of, and attitudes towards, clients with mental health and AOD problems. Education should focus on the recognition and care of people with specific mental disorders rather than on mental disorders in general. It is essential that education also focuses on understanding and caring for people with AOD problems. Educational interventions should focus on aligning beliefs about public perceptions with personal beliefs about people with mental disorders and AOD problems.
Strengths and limitations of this study

- The study contained a national sample of paramedics, and respondents completed the survey anonymously.

- A limitation is the cross-sectional, self-report nature of the data.

- Another limitation is that, because there was no observable component to the study, it is unclear if attitudes towards the individuals depicted in the vignettes were translated into paramedics' routine practice when caring for people with these issues.

\section{INTRODUCTION}

People with mental health and alcohol and other drug (AOD) problems experience high levels of stigma. Stigma refers to negative attitudes towards people with these problems, and comprises negative stereotypes, prejudices and discriminatory behaviour. ${ }^{1}$ Stigma is experienced commonly by people with mental health conditions, ${ }^{1-3}$ including depression, ${ }^{45}$ and AOD problems. ${ }^{6}$ However, the level of stigma experienced varies, and while there has been some conflicting reports of reduced stigmatisation towards people with depression over recent years, there has been little change in community attitudes towards those with psychosis and AOD misuse. ${ }^{78}$ Mental health problems that involve psychosis are stigmatised more so than non-psychosis related mental health problems. ${ }^{9}$ As well, AOD misuse is more highly stigmatised than mental health conditions. A systematic review of stigma in 17 population studies concluded that, in comparison with other substance-unrelated mental disorders, individuals with alcohol-dependence are especially stigmatised including being blamed for their 
predicament, are more likely to provoke social rejection and experience discrimination. ${ }^{6}$ Moreover, people experiencing mental health and/or AOD problems are often perceived as 'blameworthy', 'dangerous', 'unpredictable', 'weak-willed' and 'morally compromised', when compared with people experiencing physical health problems. ${ }^{9}{ }^{10}$ Men with mental health issues are particularly viewed as 'dangerous', with participants in a general population survey of mental health attitudes reporting a desire for greater social distance from men with mental health problems. ${ }^{9}$ Furthermore, people in recovery encounter similar levels of stigma to people with current problems, indicating general pessimism about people's ability to change and recover. ${ }^{11}$

A major implication of stigma is it can act as a helpseeking barrier, ${ }^{211}$ especially in men where help-seeking is already low. ${ }^{12} 13$ Given this situation, when men do seek help it is important they receive the right support, and the support should not reinforce stigma. For men, activities associated with help-seeking, such as relying on others, admitting a need for help, and recognising or labelling an emotional problem, also conflict with the messages they receive about the importance of self-reliance, physical toughness and emotional control. ${ }^{12}{ }^{14}$ Consequently, when men do present for help, it is most often for an acute physical illness or crisis, rather than mental health or chronic conditions as the primary complaint. ${ }^{15} 16$ Given their limited contact with health professionals, it is important that when men do make contact, their mental health needs are appropriately identified, and early, targeted interventions are applied. ${ }^{15}$

Paramedics are well placed to identify and respond to clients with mental health and/or AOD problems, particularly as their role increasingly involves providing emergency mental healthcare. ${ }^{17} 18$ Indeed, recent evidence suggests that a significant proportion of their workload involves transporting clients with difficult and complex issues involving mental health, AOD and/or self-harm. ${ }^{19}$ In Australia, 1-in- $5^{20} 21$ to 1 -in- $10^{22}$ ambulance presentations involve clients with these conditions. Similar experiences with these client groups have been reported in the USA, ${ }^{23} \mathrm{UK}^{24}$ Canada $^{25}$ and Russia. ${ }^{26}$ Traditionally, however, the training paramedics receive focuses primarily on life-threatening emergencies, trauma and resuscitation. ${ }^{18}$ Inadequate mental health and/or AOD training can undermine their competence and willingness to care for clients with these problems. ${ }^{1727-30}$

Studies exploring health professionals' attitudes towards people with mental health and/or AOD problems have illustrated differences in levels of stigmatising attitudes between these disciplines. For instance, one study has shown that general practitioners (GPs) hold more stigmatising attitudes than psychologists and psychiatrists. ${ }^{31}$ Reavley $e t a l^{31}$ suggested that high levels of work pressure and low levels of training and awareness in relation to mental health are potential reasons for the stigmatising attitudes reported by GPs in this study. High work pressures and limited mental health training have been identified in relation to paramedics, ${ }^{29} 32$ and so following Reavley et $a l \mathrm{~s}^{31}$ suggestions, one might expect that paramedics hold stigmatising attitudes similar to GPs. However, limited research has been conducted into paramedics' attitudes, although some studies of undergraduate paramedics show differing attitudes towards clients with mental health and AOD problems. One study explored the attitudes of undergraduate students in health science disciplines, including paramedicine, and found that students had strong regard for clients with intellectual disabilities and moderate regard for those with acute mental health problems, but much more negative attitudes towards clients with AOD problems. ${ }^{33}$ It is unclear, however, if these attitudes persist when students enter the paramedic workforce, further highlighting the need to examine paramedics' attitudes towards clients with mental health and/or AOD problems. The aims of this paper were to assess paramedics' ability to recognise, and their attitudes towards, clients with clinically defined depression and psychosis with and without comorbid AOD problems. Given existing literature on stigma and health professionals, we anticipated that the attitudes would be potentially worse towards clients with psychosis than those with depression, and these would be even worse towards those with comorbid alcohol/drug problems.

\section{METHODS}

\section{Study design}

An online, cross-sectional survey, which took approximately $15 \mathrm{~min}$ to complete, was promoted to paramedics across Australia between April and November 2016. The survey formed part of a larger study which also included qualitative interviews with paramedics.

\section{Sample and recruitment}

All paramedics employed in ambulance services in six of the eight Australian states and territories were invited to participate in the study. Recruitment occurred though multiple communication channels, including emails, e-newsletters and bulletins from each participating ambulance service, as well as promotion through Paramedics Australasia's newsletter and website.

The first page of the online survey contained information about the study and what participation involved. It also stated that completion of the survey was interpreted as consent.

\section{Patient and public involvement}

Neither patients nor public were involved in the development of the research question, study design, outcome measures, recruitment to and conduct of the study. The results of the study will be disseminated to participants through lectures presented by the investigators and to ambulance service representatives. 


\section{Instruments}

The Scales to Assess Mental Health Literacy (SAMHL) ${ }^{34}$ were used to assess mental health literacy and attitudes towards people with mental health and substance use problems. The Scales contained four, slightly modified vignettes: depression with suicidal thoughts (depression vignette), depression with suicidal thoughts and alcohol problems (depression and AOD vignette), psychosis (psychosis vignette) psychosis and illicit drug use (psychosis and AOD vignette). The vignettes were based on the diagnostic criteria of the Diagnostic and Statistical Manual of Mental Disorders, Fourth Edition ${ }^{35}$ and the ICD-10 Classification of Mental and Behavioural Disorders: Clinical Descriptions and Diagnostic Guidelines, ${ }^{36}$ and have been used extensively to assess mental health literacy in the general Australian community, as well as other first responder groups that regularly encounter clients with mental illness in the course of their work. ${ }^{937}$ Each vignette was followed by the same 20 items about the respondent's own attitudes towards the person in the vignette (personal stigma) $(n=9)$ and the respondent's beliefs about others' attitudes towards the person in the vignette (perceived social stigma) $(n=9)$, plus two items about what was wrong with the person in the vignette (free-text response) and frequency of professional contact with clients with this issue (close-ended). ${ }^{37}$ The 18 items are rated on a five-point Likert scale, from 1 (strongly agree) to 5 (strongly disagree). Consistent with previous work, ${ }^{38}$ survey respondents were assigned randomly to one of the two vignettes relating to depression and one of the two vignettes relating to psychosis. In addition, each respondent responded to at least one scenario that involved alcohol or drugs to enable us to compare how paramedics' attitudes towards clients with mental health presentations may have differed when alcohol and drugs were involved. The internal reliability of the SAMHL has been ascertained previously. The Cronbach's alpha in the present study was 0.83 for the depression vignette, 0.80 for the depression with AOD vignette, 0.76 for the psychosis vignette, and 0.82 for the psychosis with AOD vignette.

The Social Distance Scale (SDS) ${ }^{39}$ was used to assess willingness to have contact with the person depicted in the vignette. The scale contains five items rated on a five-point Likert scale, from 1 (strongly disagree) to 5 (strongly agree), with higher scores indicative of higher level of stigma. The internal reliability of the SDS has been established previously. The Cronbach's alpha in this study was 0.81 for the depression vignette, 0.82 for the depression with AOD vignette, 0.85 for the psychosis vignette and 0.85 for the psychosis with AOD vignette.

\section{Statistical analysis}

Analyses were conducted using Stata for Windows, V.13.1. (StataCorp, 2013) To determine the proportion of respondents correctly identifying the mental disorder portrayed in each vignette, open-text responses to the 'recognition' question were coded by one of the authors
(NF) into categories for analysis. Similar to the approach used in studies using the same vignette approach, ${ }^{32}$ a response was considered correct if it mentioned the exact term of the condition in the vignette (eg, 'psychosis'), a synonym or slight variant on that term (eg, 'psychotic episode' or 'schizophrenia', etc). A different author (MS) checked the coding independently and confirmed that coding decisions were accurate. Data were then analysed by calculating percent frequencies and their $95 \%$ CIs. For each item on the SDS, we calculated the proportion of respondents either agreeing or strongly agreeing with each statement, using the Fisher's Exact Test to investigate whether there was any significant difference in the proportion of respondents either agreeing or strongly agreeing to each statement in the vignette that featured comorbid AOD problems as compared with the vignette without comorbid AOD problems.

\section{RESULTS}

A total of 1230 paramedics completed the survey (equivalent to approximately $7.3 \%$ of the ambulance officer and paramedic workforce of $16800^{40}$; however, $77(0.06 \%)$ of these did not provide answers beyond starting the survey. As such, the following results are based on the 1152 who continued with the survey. The sample size was approximately representative of the overall workforces in New South Wales, Northern Territory, Queensland, Tasmania, Victoria, in terms of age, years of experience and professional designation. However, in light of the smaller sample sizes from Australian Capital Territory, South Australia and Western Australia, no claims are made about representativeness to their workforces. Two-thirds were male $(\mathrm{n}=761 ; 66.2 \%)$, and respondents had an average age of 41 years. Just over $40 \%$ had a bachelor-level qualification $(n=498,43.6 \%)$ and were employed as a general care paramedic $(n=491,42.8 \%)$. Respondents had been employed as a paramedic for an average of 13 years. Once randomised to one of the four vignette conditions, respondents indicated whether they had daily or weekly contact with a patient experiencing similar symptoms to the vignette scenario. Just over two-thirds of respondents indicated they had daily or weekly contact, in the course of their employment, with clients experiencing comorbid depression and AOD problems $(68.2 \%)$, followed by depression without AOD problems $(67.2 \%)$, while less than half had daily or weekly contact with clients with psychosis with comorbid AOD problems $(44.2 \%)$, and psychosis without AOD problems $(40.8 \%)$. Around half of those who responded had received little or no prequalification or ongoing professional education and training about caring for clients with depression or psychosis, while a quarter to a third had received little or no education about AOD problems such as intoxication with alcohol and/or drugs (table 1). Rates of missing data were low for all variables, ranging from $0 \%$ to $3 \%$ and with all but one variable below $1 \%$. Given the large sample, it was considered unlikely that 
Open access

Table 1 Sociodemographic and employment characteristics

\begin{tabular}{|c|c|c|}
\hline Characteristic & Mean & SD \\
\hline Age (years) $(n=1145)$ & 41.0 & 10.9 \\
\hline \multirow[t]{2}{*}{ Duration of employment as paramedic $(n=1118)$} & 13.3 & 9.8 \\
\hline & $\mathbf{n}$ & $\%$ \\
\hline \multicolumn{3}{|l|}{ Sex $(n=1151)$} \\
\hline Male & 761 & 66.1 \\
\hline Female & 389 & 33.8 \\
\hline Unknown/other & 1 & 0.1 \\
\hline \multicolumn{3}{|l|}{ Aboriginal or Torres Strait Islander $(n=1150)$} \\
\hline Yes & 27 & 2.3 \\
\hline No & 1123 & 97.7 \\
\hline \multicolumn{3}{|l|}{ State of employment $(n=1150)$} \\
\hline Australian Capital Territory & 1 & 0.1 \\
\hline New South Wales & 413 & 35.9 \\
\hline Northern Territory & 36 & 3.1 \\
\hline Queensland & 361 & 31.4 \\
\hline South Australia & 51 & 4.4 \\
\hline Tasmania & 57 & 5.0 \\
\hline Victoria & 229 & 19.9 \\
\hline Western Australia & 2 & 0.2 \\
\hline \multicolumn{3}{|l|}{ Geographical location of employment $(n=1151)$} \\
\hline Metropolitan & 548 & 47.6 \\
\hline Regional & 312 & 27.1 \\
\hline Rural & 256 & 22.2 \\
\hline Remote & 35 & 3.0 \\
\hline \multicolumn{3}{|l|}{ Paramedic role $(n=1148)$} \\
\hline General care paramedic & 491 & 42.8 \\
\hline Paramedic manager & 177 & 15.4 \\
\hline Intensive care paramedic & 162 & 14.1 \\
\hline Other & 112 & 9.8 \\
\hline Extended care paramedic & 91 & 7.9 \\
\hline Ambulance officer & 63 & 5.5 \\
\hline Graduate intern & 35 & 3.0 \\
\hline Flight paramedic & 11 & 0.9 \\
\hline Retrieval paramedic & 2 & 0.2 \\
\hline First responder & 2 & 0.2 \\
\hline Patient transport attendant & 2 & 0.2 \\
\hline
\end{tabular}

Frequency of daily or weekly contact with client group $(\mathrm{n}=519)$

\begin{tabular}{lll}
\hline Depression with AOD problems & 354 & 68.2 \\
\hline Depression without AOD problems & 344 & 67.2 \\
\hline $\begin{array}{l}\text { Psychosis with AOD problems } \\
\text { Psychosis without AOD problems }\end{array}$ & 214 & 44.2 \\
$\begin{array}{l}\text { Extent to which prequalification education and training } \\
\text { addressed assessment and management of clients who } \\
\text { are: }\end{array}$ & $\begin{array}{l}\text { None/little, } \\
\%(\mathbf{n})\end{array}$ & 40.8 \\
\hline \begin{tabular}{l} 
Depressed or have low mood \\
\hline
\end{tabular} & $54.6(672)$ & $\begin{array}{l}\text { Moderately/great extent, \% } \\
\text { (n) }\end{array}$ \\
\hline
\end{tabular}


Table 1 Continued

\begin{tabular}{|c|c|c|}
\hline Characteristic & Mean & SD \\
\hline Age (years) $(n=1145)$ & 41.0 & 10.9 \\
\hline Duration of employment as paramedic $(n=1118)$ & 13.3 & 9.8 \\
\hline Paranoid and/or hallucinating & $49.1(604)$ & $27.5(339)$ \\
\hline Intoxicated with alcohol and/or drugs & $25.3(312)$ & $51.3(631)$ \\
\hline Depressed or have low mood & $51.8(637)$ & $24.8(305)$ \\
\hline Paranoid and/or hallucinating & $48.7(599)$ & $27.9(343)$ \\
\hline Intoxicated with alcohol and/or drugs & $32.5(400)$ & $44.1(542)$ \\
\hline
\end{tabular}

AOD, alcohol and other drug.

this degree of missing data would contribute to bias in the data. ${ }^{41}$

\section{Recognition}

Of the 505 respondents randomised to the depression without comorbid AOD problems vignette, around one-half $(48.5 \%)$ mentioned correctly 'depression' and either 'suicidal ideation', 'suicidal thoughts', 'self-harm' or 'suicide'. Of the 516 respondents randomised to the depression with comorbid AOD problems vignette, one-fifth (20.3\%) mentioned correctly depression, suicidal ideation and/or behaviour, and either 'alcohol problems', 'problematic alcohol use', 'alcoholism', 'problematic drinking' or 'substance misuse' (table 2).

Of the 469 respondents randomised to the psychosis without comorbid AOD problems vignette, most (87.6\%) mentioned correctly either 'schizophrenia', 'delusions', 'hallucinations', 'paranoia', 'psychosis' or 'psychotic episode'. Of the 475 respondents randomised to the psychosis with comorbid AOD problems vignette, over one-half (58.3\%) mentioned correctly 'psychosis' and either 'cannabis', 'drugs', 'drug induced psychosis' or 'substance misuse' (table 2).

\begin{tabular}{|c|c|c|}
\hline Vignette & $\begin{array}{l}\text { Correct } \\
\text { recognition, \% } \\
(95 \% \mathrm{Cl})\end{array}$ & Total, $\mathbf{n}$ \\
\hline Depression & 48.5 (44.2 to 52.9 ) & 505 \\
\hline $\begin{array}{l}\text { Depression with comorbid } \\
\text { AOD }\end{array}$ & 20.3 (17.1 to 24.0$)$ & 516 \\
\hline Psychosis & 87.6 (84.3 to 90.3$)$ & 469 \\
\hline $\begin{array}{l}\text { Psychosis with comorbid } \\
\text { AOD }\end{array}$ & 58.3 (53.8 to 62.7$)$ & 475 \\
\hline
\end{tabular}

AOD, alcohol and other drug.

\section{Personal stigma}

Respondents were asked to indicate the extent to which they agreed with several statements concerning common stigmatising attitudes towards people with depression and psychosis with and without comorbid AOD problems. Respondents were most likely to either agree or strongly agree with the statement that people with psychosis and AOD problems are more unpredictable than those with psychosis only (table 3 ).

For the depression vignettes, respondents were significantly more likely to endorse the statement relating to an unwillingness to employ someone with a mental health problem where the vignette featured comorbid AOD problems (table 3). For the psychosis vignettes, respondents were significantly more likely to endorse statements relating to personal weakness, dangerousness, unpredictability, employability and an unwillingness to vote for a politician experiencing mental illness where the vignette featured comorbid AOD problems (table 3).

\section{Perceived social stigma by others}

Respondents were asked to indicate the extent to which they believed others would agree with these same nine statements. For the depression vignettes, respondents were significantly more likely to believe that others would endorse the statement relating to an unwillingness to employ someone with a mental health problem where the vignette featured comorbid AOD problems (table 4). For the psychosis vignettes, respondents were significantly more likely to believe that others would endorse statements relating to being able to 'snap out of it', personal weakness, whether the problem was a real medical illness, avoidance, employability and unwillingness to vote for a politician where the vignette featured comorbid AOD problems (table 4).

\section{Social distance}

Respondents were asked if they would be willing to spend time with someone experiencing depression and 


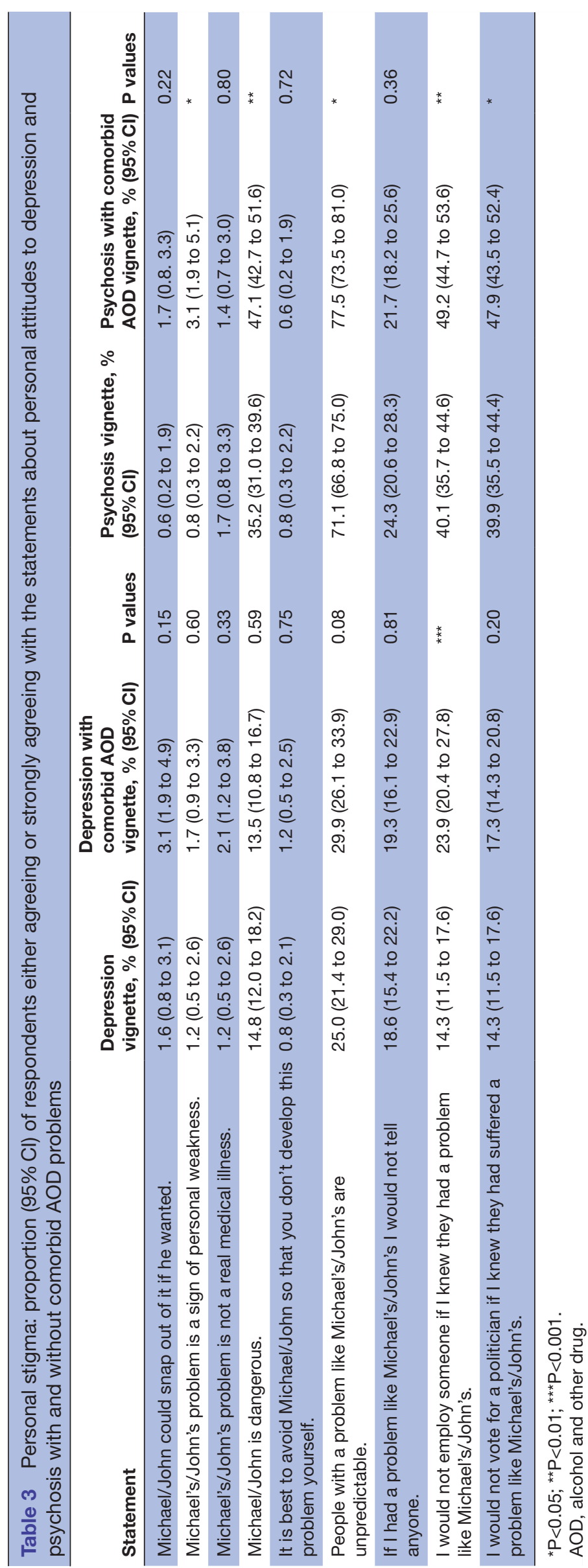




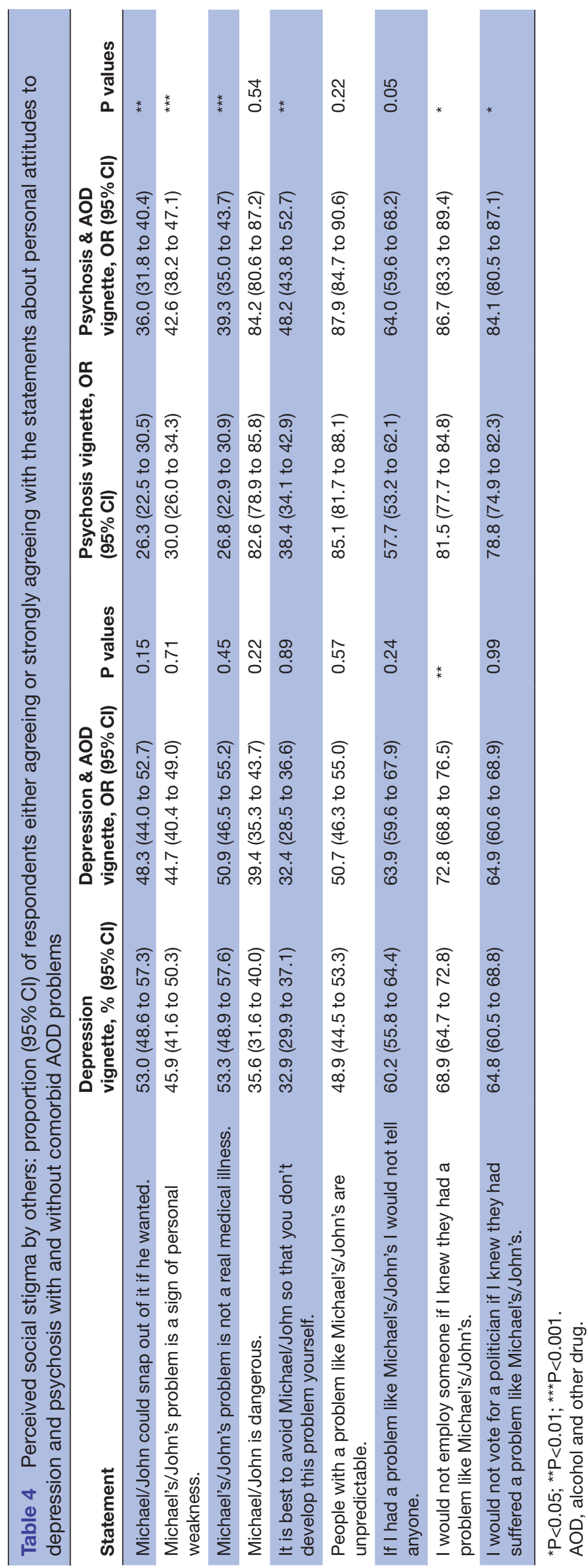


psychosis with and without comorbid AOD problems across a range of different scenarios. Respondents were significantly more likely to state that they were probably or definitely unwilling to spend time with someone experiencing depression with comorbid AOD problems across each of the scenarios, compared with depression alone. Similarly, they were significantly more likely to be probably or definitely unwilling to spend time with someone experiencing psychosis with comorbid AOD problems across all but one of the scenarios (unwilling to move next door to), compared with psychosis alone (table 5).

\section{DISCUSSION}

This paper presents the findings of a national study of paramedics' recognition of, personal and perceived social stigma towards, and desire for social distance from, people described in the following vignettes: depression and psychosis with and without comorbid AOD problems. The findings show that, in the course of their employment, respondents reported more frequent contact with clients experiencing depression with and without AOD problems than with those experiencing psychosis with and without AOD problems. Nevertheless, at least $40 \%$ reported daily or weekly contact with the latter client group. This difference may be attributable, in part, to a much lower 12 month and lifetime prevalence of psychosis than depression, ${ }^{42}$ and this is reflected in the number of these clients being transported to emergency departments by paramedics. ${ }^{20}$

\section{Recognition}

Regarding recognition of clients with these diagnoses, just under half of respondents were able to recognise depression, but this decreased markedly to one-fifth when comorbid AOD problems were added to the vignette. In contrast, almost $90 \%$ of respondents were able to recognise psychosis; however, this decreased to just under $60 \%$ when comorbid AOD problems were added. A lower proportion of our respondents recognised depression compared with a national survey of the general population in Australia (48.5\% vs $86 \%$ ). ${ }^{9}$ Interestingly however, we found respondents were much better than the general population at recognising psychosis $(87.6 \%$ vs $31.9 \%) .{ }^{9} \mathrm{~A}$ possible explanation for the differences between recognition of depression and psychosis (with and without AOD problems) in our study is that paramedics are more likely to have frequent contact with people with psychosis (a low prevalence disorder) than the general population. In comparison with psychosis, depression is more common in the general population and has been the focus of numerous public health and health promotion campaigns. Another explanation is that psychosis is more likely to be regarded as an acute presentation, which is treated within a more medical-like model of care (eg, treatment of acute behavioural disturbance), and this aligns more closely with paramedic's general practice. In contrast, depression per se is less likely to be recognised

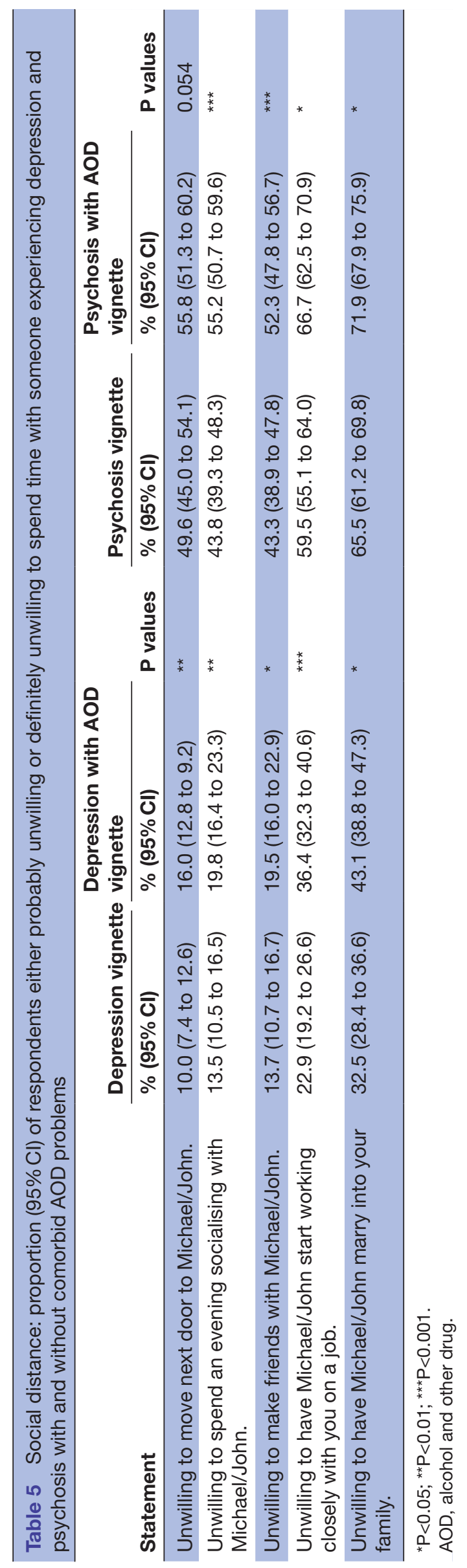


because it is viewed as a primary health issue rather than an emergency requiring paramedic care and, therefore, is undervalued in assessment and training frameworks. Furthermore, apart from severe depression and/ or suicide attempt, the symptoms of depression may be more subtle and less likely to be detected by paramedics.

\section{Personal and perceived stigma}

Concerning personal stigma, the findings show that our respondents were more likely to hold stigmatising attitudes towards people in the vignettes with depression and those with psychosis when comorbid AOD problems were present. This suggests that AOD problems were particularly stigmatising. It is noteworthy that the proportion of respondents either agreeing or strongly agreeing to many of the personal stigma items was lower than the general population for most items, including 'snap out of it', 'sign of personal weakness', 'problem is not real medical illness' and 'avoidance of the person'. ${ }^{43}$ However, there were differences to the general population too, with a greater proportion of our respondents reporting dangerousness for both psychosis vignettes, not employing a person with the problem for both psychosis vignettes, and not voting for a politician with psychosis and comorbid AOD problems (but not for psychosis only) ${ }^{43}$ Almost universally, the proportion of our respondents endorsing each statement was worse for the comorbid AOD vignettes, which may reflect the fact that AOD problems are often more highly stigmatised than mental health problems in society. ${ }^{44}$ In addition, context may have influenced these responses, as the potential for AOD-related violence and unpredictable behaviour is a prominent concern of paramedics ${ }^{45} 46$ (and clinicians in emergency departments). ${ }^{47}$

In relation to perceived social stigma by others, overall, similar proportions of respondents endorsed the attitudinal statements for depression with or without comorbid AOD problems. However, a significantly greater proportion would not employ someone with depression and comorbid AOD problems compared with a person with depression only. For the psychosis vignettes, there were significant differences between respondents in several statements ('snap out of it', personal weakness, whether the problem was a real medical illness, avoidance and employability), when the person highlighted in the vignette had comorbid AOD problems. This indicates that psychosis with AOD problems was perceived by others as especially stigmatising. This may be attributable, in part, to the success of public health campaigns to normalise depression and people with depression (that it's okay and common and it's not your fault). In contrast, long-held associations between AOD problems (in particular) and harms to others, violence and loss of control have largely been unchallenged by public health advocates, and are actively drawn on in public health, media campaigns and the film industry to reinforce stigma. ${ }^{48}$ There is also a link between schizophrenia, comorbid AOD problems and risk of violence. A systematic review and meta-regression analysis of 110 studies, for risk factors for violence in psychosis (mostly schizophrenia), concluded that, for example, recent substance misuse and a history of criminal history were significant risk factors for violence. ${ }^{49}$ Furthermore, and within the context of paramedic attendance, these clinicians are called on predominantly when the problem is often at an acute stage and the person is at risk of harming themselves or others.

Overall, similar to others studies assessing stigmatising attitudes, ${ }^{43}{ }^{50}$ the respondents in our study endorsed the questionnaire items assessing perceived social stigma more highly than personal stigma. A social desirability effect $^{51}$ may have influenced this finding; however, the fact that the survey was conducted online suggests this may not fully explain the large difference in responses. Another explanation for this difference is that increased awareness of community stigma may have resulted in an over-estimation of such beliefs in respondents. ${ }^{43}$

\section{Social distance}

With regard to social distance, respondents reported that they were probably or definitely unwilling to spend time with a person with depression and someone with psychosis across most or all scenarios when comorbid AOD problems also existed. Additionally, the desire for social distance was greater in the vignettes focusing on psychosis with and without comorbid AOD problems compared with depression with and without comorbid AOD problems. These findings suggest that desire for social distance was greater in responses to the psychosis vignettes compared with the depression vignettes possibly because of the perceived higher level of dangerousness and unpredictability in people with psychosis compared with depression. ${ }^{10} 4352$ Lack of education about mental health and AOD problems can also reinforce this perception and may have implications for willingness to deal with people with these issues. ${ }^{1727-30}$

Strengths of this study are it contained a national sample of paramedics, and the respondents completed the survey anonymously. Study limitations include the cross-sectional, self-report nature of the data, including the possibility that responses may have been influenced by a social desirability bias, and practice intentions were not assessed. In addition, as a convenience sample, the responses may not be generalisable. However, the findings provide an important insight into this representative sample (approximately $7.3 \%$ of the workforce ${ }^{40}$ ) of paramedic respondents' recognition of, and attitudes towards, people with depression and psychosis with and without comorbid AOD problems. Another limitation is, the finding about paramedics' claimed frequency of contact with clients with mental health and/or AOD misuse, has to be interpreted within the context of their variable ability to recognise clients with these diagnoses. A final limitation is that, because there was no observable component to the study, it is unclear if attitudes towards the individuals depicted in the vignettes were translated into paramedics' routine practice when caring for people with these problems. 


\section{CONCLUSION}

Paramedics have a critical first-responder role in caring for people with mental disorders and/or AOD problems. While it does not necessarily follow that negative attitudes and desire for social distance lead to discriminatory care and treatment, ${ }^{53}$ in many instances these attitudes may have adverse implications for paramedics' professional behaviour, clinical decision-making and quality of care for, and subsequent treatment access by, patients with mental health and/ or AOD problems and for paramedic peers. ${ }^{54}$ In promoting more favourable attitudes, paramedics require a well-crafted multicomponent response which addresses cultural change within their organisations and provides additional prequalification and continuing professional education to enhance their recognition of, and attitudes towards, caring for clients with mental health and AOD problems. Evidence-based and contact-based education with patients who have achieved significant recovery from mental health and/or AOD problems ${ }^{54}$ coupled with positive role modelling and mentorship by experienced peers (educational and clinical), ${ }^{55}$ is more likely to be successful in improving attitudes if it focuses on the recognition and care of people with specific mental disorders rather than on mental disorders in general. ${ }^{43}$ There is also a need to address perceptions of dangerousness and unpredictability in people with psychosis. In addition, it is important that education has a specific focus on understanding and caring for people with AOD problems. Finally, educational interventions need to focus on aligning beliefs about public perceptions with personal beliefs about people with mental disorders and AOD problems. ${ }^{43}$

\section{Author affiliations \\ ${ }^{1}$ Department of Nursing and Midwifery, Institute of Health and Sport, Victoria University, Melbourne, Victoria, Australia \\ ${ }^{2}$ Turning Point, Eastern Health, Melbourne, Victoria, Australia \\ ${ }^{3}$ Eastern Health Clinical School, Monash University, Melbourne, Victoria, Australia \\ ${ }^{4}$ Department of Rural Nursing and Midwifery, College of Health, Science and \\ Engineering, La Trobe University, Bendigo, Victoria, Australia \\ ${ }^{5}$ Queensland Ambulance Service, Brisbane, Victoria, Australia \\ ${ }^{6}$ Ambulance Victoria, Melbourne, Victoria, Australia \\ ${ }^{7}$ College of Medicine and Public Health, Flinders University, Adelaide, South Australia, Australia}

Acknowledgements Our thanks to the paramedics who participated and to the ambulance services that actively promoted the study. Our thanks also to the following ambulance service representatives for their valuable contribution to the project: Kevin McLaughlin and Dr Rosemary Carney, Ambulance Service of New South Wales; Alex Wilson, Ambulance Tasmania; Melanie Thorrowgood, South Australia Ambulance Service; Michael McKay and Sue-Ellen Skinner, St John Ambulance Northern Territory. Finally, our thanks to the Project Steering Committee members for their indispensable guidance in the project.

Contributors DIL, TVMC, MS, KE, EB, LR and KS designed the study. NF and KE collected the data. $\mathrm{AC}$ and $\mathrm{KW}$ analysed the data. All authors participated actively in the writing of the manuscript and approved the final draft.

Funding This work was supported by a grant from Beyondblue (http://www. beyondblue.org.au/), using donations from the Movember Foundation (http://au. movember.com/), grant number AN: CLT:7156.

Competing interests None declared.

Patient consent Not required.

Ethics approval Ethics approval to conduct the study was obtained from local human research ethics committees across Australian states and territories (including the committees for Eastern Health (Victoria), South Australia Department for Health and Ageing, South Eastern Sydney Local Health District, Flinders University (South Australia)). The remaining states and territories accepted ethics approval from another jurisdiction. Approval was also obtained from each ambulance service research committee or structure.

Provenance and peer review Not commissioned; externally peer reviewed.

Data sharing statement All relevant data are contained in the paper.

Open access This is an open access article distributed in accordance with the Creative Commons Attribution Non Commercial (CC BY-NC 4.0) license, which permits others to distribute, remix, adapt, build upon this work non-commercially, and license their derivative works on different terms, provided the original work is properly cited, appropriate credit is given, any changes made indicated, and the use is non-commercial. See: http://creativecommons.org/licenses/by-nc/4.0/.

\section{REFERENCES}

1. McGinty EE, Goldman HH, Pescosolido B, et al. Portraying mental illness and drug addiction as treatable health conditions: effects of a randomized experiment on stigma and discrimination. Soc Sci Med 2015;126:73-85.

2. Corrigan PW, Druss BG, Perlick DA. The impact of mental illness stigma on seeking and participating in mental health care. Psychol Sci Public Interest 2014:15:37-70.

3. Corrigan PW. Challenging the stigma of mental illness: different agendas, different goals. Psychiatr Serv 2015;66:1347-9.

4. Conner KO, McKinnon SA, Ward CJ, et al. Peer education as a strategy for reducing internalized stigma among depressed older adults. Psychiatr Rehabil J 2015;38:186-93.

5. Griffiths KM, Christensen H, Jorm AF. Predictors of depression stigma. BMC Psychiatry 2008;8:1-12.

6. Schomerus G, Lucht M, Holzinger A, et al. The stigma of alcohol dependence compared with other mental disorders: a review of population studies. Alcohol Alcohol 2011;46:105-12.

7. Norman RM, Windell D, Manchanda R. Examining differences in the stigma of depression and schizophrenia. Int J Soc Psychiatry 2012;58:69-78.

8. Corker EA, Beldie A, Brain C, et al. Experience of stigma and discrimination reported by people experiencing the first episode of schizophrenia and those with a first episode of depression: the FEDORA project. Int J Soc Psychiatry 2015;61:438-45.

9. Reavley NJ, Jorm AF. Recognition of mental disorders and beliefs about treatment and outcome: findings from an Australian national survey of mental health literacy and stigma. Aust N Z J Psychiatry 2011;45:947-56.

10. Corrigan PW, Larson JE, Rüsch N. Self-stigma and the why try effect: impact on life goals and evidence-based practices. World Psychiatry 2009;8:75-81.

11. Phillips LA, Shaw A. Substance use more stigmatized than smoking and obesity. J Subst Use 2013;18:247-53.

12. Wendt D, Shafer K. Gender and attitudes about mental health help seeking: results from national data. Health Soc Work 2016;41:e20-8.

13. Roskar S, Bracic MF, Kolar U, et al. Attitudes within the general population towards seeking professional help in cases of mental distress. Int J Soc Psychiatry 2017;63:614-21.

14. Addis ME, Mahalik JR. Men, masculinity, and the contexts of help seeking. Am Psychol 2003;58:5-14.

15. Cleary $A$. Help-seeking patterns and attitudes to treatment amongst men who attempted suicide. J Ment Health 2017;26:220-4.

16. Galdas PM, Cheater F, Marshall P. Men and health help-seeking behaviour: literature review. J Adv Nurs 2005;49:616-23.

17. Parsons V, O'Brien L, O'Meara P. Mental health legislation: an era of change in paramedic clinical practice and responsibility. International Paramedic Practice 2011;1:9-16.

18. Rees N, Rapport F, Snooks H, et al. How do emergency ambulance paramedics view the care they provide to people who self harm?: Ways and means. Int J Law Psychiatry 2017;50:61-7.

19. Booth A, Scantlebury A, Hughes-Morley A, et al. Mental health training programmes for non-mental health trained professionals coming into contact with people with mental ill health: a systematic review of effectiveness. BMC Psychiatry 2017;17:196.

20. Lloyd B, Gao CX, Heilbronn C, et al. Self-harm and mental healthrelated ambulance attendances in Australia: 2013 data. Fitzroy, Victoria: Turning Point, 2015.

21. ABC News. Mental health issues making up one in five visits for paramedics in Victoria: ABC, 2015.

22. Roggenkamp R, Andrew E, Nehme Z, et al. Descriptive analysis of mental health-related presentations to emergency medical services. Prehosp Emerg Care 2018;22:399-405. 
23. Cloutier RL, Hendrickson RG, Fu RR, et al. Methamphetaminerelated psychiatric visits to an urban academic emergency department: an observational study. J Emerg Med 2013;45:136-42.

24. Rees N, Rapport F, Thomas G, et al. Perceptions of paramedic and emergency care workers of those who self harm: a systematic review of the quantitative literature. J Psychosom Res 2014;77:449-56.

25. Richards JR, Hamidi S, Grant CD, et al. Methamphetamine use and Emergency Department utilization: 20 years later. J Addict 2017;2017:1-8.

26. Walley AY, Cheng DM, Quinn EK, et al. Fatal and non-fatal overdose after narcology hospital discharge among Russians living with HIV/ AIDS who inject drugs. Int J Drug Policy 2017;39:114-20.

27. Hou XY, Rego J, Service M. Review article: Paramedic education opportunities and challenges in Australia. Emerg Med Australas 2013;25:114-9.

28. Prener C, Lincoln AK. Emergency medical services and psych calls: examining the work of urban EMS providers. Am J Orthopsychiatry 2015;85:612-9.

29. Roberts L, Henderson J. Paramedic perceptions of their role, education, training and working relationships when attending cases of mental illness. AJP 2009;7.

30. Townsend R, Luck M. Protective jurisdiction, patient autonomy and paramedics: the challenges of applying the NSW Mental Health Act. AJP 2009; 7:1-11.

31. Reavley NJ, Mackinnon AJ, Morgan AJ, et al. Stigmatising attitudes towards people with mental disorders: a comparison of Australian health professionals with the general community. Aust $N Z J$ Psychiatry 2014;48:433-41.

32. Sterud T, Ekeberg $\varnothing$, Hem E. Health status in the ambulance services: a systematic review. BMC Health Serv Res 2006;6:82.

33. Boyle MJ, Williams B, Brown T, et al. Attitudes of undergraduate health science students towards patients with intellectual disability, substance abuse, and acute mental illness: a cross-sectional study. BMC Med Educ 2010;10:71.

34. Reavley NJ, Morgan AJ, Jorm AF. Development of scales to assess mental health literacy relating to recognition of and interventions for depression, anxiety disorders and schizophrenia/psychosis. Aust N Z J Psychiatry 2014;48:61-9.

35. American Psychiatric Association. Diagnostic and statistical manual of mental disorders. Fourth Edition. Washington, DC: APA, 1994.

36. World Health Organization. ICD-10: The ICD-10 Classification of mental and behavioural disorders: clinical descriptions and diagnostic guidelines. Geneva: World Health Organization, 2000.

37. Reavley NJ, Jorm AF. Associations between beliefs about the causes of mental disorders and stigmatising attitudes: Results of a national survey of the Australian public. Aust N Z J Psychiatry 2014;48:764-71.

38. Wright A, Harris MG, Wiggers $\mathrm{JH}$, et al. Recognition of depression and psychosis by young Australians and their beliefs about treatment. Med J Aust 2005;183:18-23.
39. Link BG, Phelan JC, Bresnahan M, et al. Public conceptions of mental illness: labels, causes, dangerousness, and social distance. Am J Public Health 1999;89:1328-33.

40. Commonwealth of Australia. Australian labour market update. Canberra, ACT: Department of Employment, 2016.

41. Tabachnick BG, Fidell LS. Using multivariate statistics. 5th edn. Boston, Massachusetts: Pearson Education, 2007.

42. Australian Bureau of Statistics. National survey of mental health and wellbeing: summary of results, 2007. Canberra: Australian Bureau of Statistics, 2008.

43. Reavley NJ, Jorm AF. Stigmatizing attitudes towards people with mental disorders: findings from an Australian National Survey of Mental Health Literacy and Stigma. Aust N Z J Psychiatry 2011:45:1086-93.

44. Corrigan PW, Watson AC, Miller FE. Blame, shame, and contamination: the impact of mental illness and drug dependence stigma on family members. J Fam Psychol 2006;20:239-46.

45. Maguire BJ, O'Meara P, O'Neill BJ, et al. Violence against emergency medical services personnel: a systematic review of the literature. Am $J$ Ind Med 2018;61:167-80.

46. Wongtongkam N. An exploration of violence against paramedics, burnout and post-traumatic symptoms in two Australian ambulance services. IJEM 2017;6:134-46.

47. Nikathil S, Olaussen A, Symons E, et al. Increasing workplace violence in an Australian adult emergency department. Emerg Med Australas 2018;30:181-6.

48. Kennedy L, Valleriani J. Everybody loves a redemption story around election time: Rob Ford and media construction of substance misuse and recovery. Can J Criminol Crim Justice 2017;59:461-97.

49. Witt K, van Dorn R, Fazel S. Risk factors for violence in psychosis: systematic review and meta-regression analysis of 110 studies. PLoS One 2013;8:e55942.

50. Griffiths $\mathrm{KM}$, Nakane $\mathrm{Y}$, Christensen $\mathrm{H}$, et al. Stigma in response to mental disorders: a comparison of Australia and Japan. BMC Psychiatry 2006;6:12.

51. Edwards AG. The social desirability variable in personality assessment and research. New York: Dryden Press, 1957.

52. Jorm AF, Griffiths KM. The public's stigmatizing attitudes towards people with mental disorders: how important are biomedical conceptualizations? Acta Psychiatr Scand 2008;118:315-21.

53. Jussim L, Nelson TE, Manis M, et al. Prejudice, stereotypes, and labeling effects: sources of bias in person perception. $J$ Pers Soc Psychol 1995;68:228-46.

54. Mittal D, Corrigan P, Sherman MD, et al. Healthcare providers' attitudes toward persons with schizophrenia. Psychiatr Rehabil $J$ 2014;37:297-303.

55. Williams A. Emotion work in paramedic practice: the implications for nurse educators. Nurse Educ Today 2012;32:368-72. 